\title{
Exploring Human Resource Management Practices in Non- Profit Sport Organisations
}

\author{
Tracy Taylor \\ University of Technology, Sydney \\ Peter McGraw \\ Macquarie University
}

KEY WORDS: sport organisations, volunteers, human resource management

Tracy Taylor is Associate Dean (Teaching and Learning) and Associate Professor, Faculty of Business, University of Technology, Sydney, PO Box 123 Broadway, NSW 2007, Australia. Peter McGraw is Director, Labour Management Studies Foundation and Associate Professor, Department of Business, Macquarie University. Email for Tracy Taylor is ttaylor@uts.edu.au

The authors would like to thank the NSW Sport Commission for their support in the conduct of this research. 
Contemporary business challenges and globalisation pressures have had a significant impact on the human resource management (HRM) practices of many organisations. Whilst the adoption of more sophisticated, complex and strategic management systems is well documented in the general HR literature, organisations that operate with both paid and volunteer human resources have been virtually ignored by scholars. In this paper we report on a study on the adoption of HRM practices by state sport organisations in New South Wales, Australia. Our results indicate that despite pressures to become more strategic in their people management, only a minority of these sport organisations have formal HRM systems. We also found differences between the HRM practices used with paid employees and volunteers particularly in organisations with formal HR policies. Research and practical implications for HRM in sport organisations are discussed as well as future challenges 
Over the past few decades representative/parent organisations of sporting activities have faced increasing pressure to adopt more sophisticated management systems and become more business oriented. In sport we have witnessed a gradual professionalisation of state and national sport organisations and a growing number of paid staff have been appointed in roles traditionally held by volunteers (Auld, 1997; Thibault, Slack \& Hinings, 1991). This has led to change management issues and tensions, as organisations transition from largely volunteer managed and governed approaches to a workforce that is a mixture of paid employees and volunteers (Nichols et al. 1998). In combination with this shift, many of these sport organisations are currently facing difficulties recruiting and retaining volunteers (Burgham \& Downward, 2005). The associated human resource issues highlight the pressing need for HRM practices to effectively manage both paid and volunteer staff in sport organisations now and into the future. In considering what HRM approaches would be most effective, the distinguishing characteristics of non-profit sport organisations should be taken into account.

The sport industry's distinctiveness is exemplified by features of intangibility, heterogeneity and inseparability of production and consumption (Buswell, 2004). Each sport organisation's existence is based on the requirement of co-ordinated, seasonal event-based competitions that are controlled by governing bodies (Beech \& Chadwick, 2004). Sport organisations that are representative/parent bodies of sport activity have been traditionally managed by sport enthusiasts with a passion for the sport, wherein measures of success are related to on-field success and participant numbers rather than to operational effectiveness. The management of these enterprises has perpetuated these distinctions by drawing heavily on a committed volunteer workforce. Therefore, current pressures to formalise management practices are juxtaposed with challenges of limited human and financial resources, reliance on volunteers, and a long tradition of informal planning, control and administrative systems. 
Concurrently, contemporary organisational discourse has espoused the need for more effective use of human resources and strategically aligned business functions to improve business outcomes and provide competitive advantage (Barney, 1991; Becker et al., 1998; Koch \& McGrath, 1996; Pfeffer, 1998). In searching for the most effective human resource management (HRM) practices, researchers have sought to identify best practice and high performance work systems (Applebaum et al., 2000; Huselid, 1995; Purcell, 1999). However, this research has predominantly focused on larger firms that employ full-time specialists and has suggested solutions appropriate for larger organisations with formal human resource systems (Nguyen \& Bryant, 2004). In Australia, empirical research has indicated high levels of formalisation in large businesses in relation to all aspects of HR policy and practice (McGraw, 2002).

In practice, organisations rarely adopt a single style of management for all their employee groups. Research on the successful adoption of strategic management practices has shown that organisational context is a critical component and that different practices work best in different environments (Purcell, 1999). This contingency perspective has particular relevance for organisations that rely on both paid employees and volunteers although there is scant research into the adoption of HRM in such organisational contexts despite calls to more strenuously pursue causes and consequences of this variability in HRM research (Boxall \& Purcell, 2000).

The research presented here investigates how state representative sport organisations in Australia have responded to pressures from both their external and internal business management environments to adopt formalised HR systems and processes. The research identifies differences between those organisations that have formalised HR and those that operate HR informally. Since non-profit sport organisations rely heavily on the effective management of employees and volunteers, we examined HR in relation to both paid staff and 
volunteers. Three basic questions were formulated: What HR practices are sport organisations formally using? What are the differences/similarities in HRM policies and practices of paid employees and volunteers? and What are the challenges influencing change in human resource management practices for paid staff and volunteers?

\section{HRM and Non-Profit Sport Organisations}

Effective HRM practices in the areas of staff selection, training, and performance management have been identified in both the theoretical and empirical HRM literature as crucial factors in helping organisations to achieve defined strategic outcomes (Purcell, 1999; Storey, 2001). Theoretically, the literature is diverse and may encompass either simple integration approaches which stress alignment of HR and business strategy (e.g., Cook \& Ferris, 1986); best practice or universalistic approaches which suggest a good outcome from investment in sophisticated HR systems, irrespective of context (e.g., Pfeffer,1998); or contingency based approaches whereby selective HR bundles are deployed to improve employee performance and provide competitive advantage (Storey, 2001) or improved business performance (Huselid, 1995). Whichever perspective is taken there seems to be universal agreement in the literature on the specific importance of effective systems in staff selection, development and the management of performance.

Notwithstanding these findings and others indicating the organisational benefits accruing from a strategic approach to HRM, many organisations still do not have clear strategies to guide their HR activities (Gratton \& Truss, 2003; Hsu \& Leat, 2000; Kane, Crawford \& Grant, 1999; Kaye, 1999). Additionally, the transferability of a generic set of management practices between industry sectors or countries still remains questionable, due to a dearth of empirical evidence and inadequate conceptual frameworks (Galang, 2004). The assumption that best practice organisations always manage in accordance with their stated policies has also been questioned, as has the influence of best practice formal HR when 
informal organisational processes are working in a contradictory manner (Truss, 2001). The effectiveness of strategic HRM approaches in non profit sport organisations is equally tinged with ambiguity. In particular, there are questions about whether research findings from large and structurally complex organisations can be tested in non-profit sport organisations which tend, on the whole, to be simple, single focus organisations.

In an article reviewing the state of organisational behaviour research in sport, Doherty (1998, p.18) commented that, "it would seem that we know relatively little about organisation effectiveness, including the contribution of human resources." In particular, despite the almost universal presence of a mixture of both paid and volunteer staff in sport organisations, systematic research on how employing this duality of human capital plays out in terms of human resource management is scarce (Chelladurai, 1999).

While not explicitly examining HRM, a number of studies have explored the impact professionalisation has had upon decision-making structures within sport organisations (Kikulis, Slack \& Hinings, 1995a, 1995b, 1995c; Slack \& Hinings, 1992, 1994; Thibault, Slack, \& Hinings, 1991). The findings suggest that perceived control over decision-making is a major source of conflict between volunteers and paid staff. As noted by McClam and Spicuza, "the relationship has been fraught with ambiguity, resistance, jealousy and tension." (1998, p.26). There is also substantive literature on volunteer boards and committees and how they function (cf. Cuskelly, McIntyre \& Boag, 1998; Doherty \& Carron, 2003; Doherty, Patterson \& Van Bussel, 2004; Hoye \& Cuskelly, 2003; Inglis, 1997; Kikulis, 2000). This research is complemented by the work exploring volunteers' experiences, commitment, motivations or characteristics (Coleman, 2002; Cuskelly, 2004; Metzer, 1996; Taylor et al., 1996). In the HR domain, it has been common to argue that volunteers need to be managed differently because they are more likely than paid employees to leave an organisation abruptly if they become dissatisfied. The main reason for this, it has been argued, is the fact 
that they do not have to find another job before deciding to leave. However, empirical studies of volunteers do not support the argument that they need to be more committed in order to remain with an organisation. Miller, Powell and Selzer (1990) for example found in a study of hospital volunteers that turnover amongst volunteers was largely explained by the same factors as turnover amongst paid employees. Notwithstanding this, little regard has been paid to the actual volunteer management practices used by organisations (Dorsch et al., 2002). Most of the work undertaken on managing volunteers as a human resource has been in the form of non- empirical "how to" manuals which provide organisations with template forms, ideas on how to reward and motivate volunteers, tips for resolving conflict and best practice examples (cf.Green, 2001). This study aims to enhance understanding of differences in management of employees and volunteers in Australian sport organisations by systematically describing and analysing how each group is selected, trained and rewarded; and how these practices relate to the level of formalisation within the organisation and the perceived future challenges.

\section{The Australian Sport Context and HRM Practices}

Non- profit sport organisations operating in Australian face several unique contexts that impact upon the possible adoption and use of HR practices. There are an estimated 1.5 million volunteers operating in the sport sector (Australian Bureau of Statistics, 2005), who contribute in excess of 165 million hours per year running sport and recreation clubs and organisations (Department of Sport \& Recreation, 2004). This reliance on volunteers has been a constant in the sport industry, despite the significant increase in numbers of paid staff. Furthermore, it is predicted that volunteers will continue to provide significant human capital in managing sport organisations (Australian Bureau of Statistics, 2000). The minimal presence of paid employees reduces the likelihood that organisations will adopt formal HR practices to manage employee relationships as such developments are usually present in 
larger organisations with HR specialists or departments (Sisson \& Storey, 2000).

Traditionally, sport organisations have relied on the volunteer's motivation and commitment to sport to take precedence over catering for the HR requirements of an individual volunteer.

However, there are several factors that are pushing organisations to become more formalised in their HRM: (1) pressure from government bodies to formalise HR practices to qualify for funding; (2) decline in membership and volunteers means there is greater competition for both; and (3) increasingly specialised staffing and compliance requirements.

First, nationally funded sport organisations that do not have formally constituted HR polices and systems have been targeted for change by government funding bodies. The Australian Sports Commission (2000) stated that national sporting organisations will face increasing levels of performance scrutiny. In particular, structure, governance, management and strategic direction have been emphasised by the Commission; with the aim of ensuring that sport organisations have the capacity and capability to deliver their strategic objectives. More recent government policy has reinforced the need for sport organisations to become more professional in their operations. The national government's sport policy stated that in the sporting sector "more can be done to enhance the quality of its management and increase its capacity to achieve its aims.... We will achieve: the adoption of sound business and management practices by national sporting organisations ... (we will) require sporting organisations to adopt sophisticated management systems" (Australian Government, 2001, pp.8-9).

Second, as levels of volunteering decline, sport organisations face the challenge of recruiting new volunteers and retaining existing ones (Sport \& Recreation Victoria, 2002). According to the Australian Bureau of Statistics (2001), sports volunteer numbers fell 14 per cent between 1997 and 2000, from 1,655,900 to 1,420,200. With an estimated 80 percent of administration in sport carried out by volunteers (Department of Sport \& Recreation, 2004), 
the decline in volunteering is a serious management issue. A formal HRM system for volunteers could provide a framework for managing their retention more systematically.

Third, sport organisations must comply with an increasing array of legislative requirements. These include the introduction of policies to respond to occupational health and safety, anti-discrimination and racial and religious vilification laws; and assessing the potential for incidents relating to harassment and abuse of children then developing strategies developed to reduce their likelihood and or severity of their occurrence (Sport \& Recreation Victoria, 2002). Compliance with statutory requirements has a cost in terms of increased workload for volunteers and sport organisation employees. The increasingly stringent legislative provisions also require those responsible for their administration to have higher order skills and knowledge. Thus, sport organisations need to consider either hiring staff or volunteers with specific legal, accountancy or other such related skill sets or providing training for these required competencies; actions which might be best located within a formalised HRM process.

As a consequence of the factors highlighted above, decisions on the adoption of HR practices and the level of formality of HR are influenced by a complex array of cultural, economic, demographic and organisational factors. While recognising the relatively informal nature of HR in non profit sport organisations, recent studies have not documented the level of adoption of HR practices or how these are used to manage paid employees and volunteers.

\section{Research Focus}

Strategies or policies on HR represent the organisation's stated intention about its HR programs, processes, and techniques. Formal HR is constituted by identifiable rules and regulations that define the employment relationship. HR practices consist of the actual programs, processes and techniques that are operationalised. HR formality is defined as the 
extent to which HR practices are systematised, documented and institutionalised through documented policies, rules and regulations. This leads to our first research question:

1. What is the extent of HR formalisation in sport organisations?

Whilst formal HR plans give some indication of an organisational approach to HR, it is also important to assess the actual practices rather than just stated policies when examining an organisation's HR (Huselid \& Becker, 2000). These practices are typically most evident in core HR areas in relation to recruitment and selection, training, performance management and rewards (Truss, 2001).

Like other industries, sport organisations have to compete for market share and scarce human resources, both paid and volunteer. The Australian Sports Commission (2000) suggested that sport organisations have minimal human resources management practices for paid staff and are unlikely to have these in place for volunteers. However, there is little empirical evidence to indicate whether this suggestion is correct or incorrect. This leads to our second and third questions:

2. To what extent are HR practices used by sport organisations in the management of paid employees and volunteers?

3. Are there differences in the HR practices used to manage paid employees and volunteers?

Previous research has indicated that organisation size is a significant predictor of HRM programs (Goodstein, 1994; Ingram \& Simons, 1995). Findings indicate that HR practices used by small organisations differ markedly from those of larger ones, with the former having more flexible, informal, unstructured and undeveloped programs (Barber et al., 1999; Bartram, 2004; de Kok \& Uhlaner, 2001). Other research (Bartram, 2004; Leung, 2004) has supported the premise that small organisations tend to use more informal human resource activities. Informality in management practice has been found to promote teamwork, 
social relations and increase employee motivation (Marlow \& Patton, 2002). However, it is also believed that informal approaches to areas such as grievance and discipline problems are problematic (Nguyen \& Bryant, 2004). This leads to our fourth and fifth research questions:

4. Is the formalisation of HR strategy related to organisational size?

5. Are formal HR practices significantly related to the perceived effectiveness of the organisation in relation to staffing?

As we have argued earlier, several factors are pushing Australian sport organisation to adopt more formalised HR system to manage staff. In brief, these factors are derived from the pressure to comply with government mandated standards and the drive for more professionalisation in the way that staff, both paid and volunteer, are managed (Cuskelly, McIntyre \& Boag, 1998). In order to examine the way that sport organisations act in response to this pressure, our final research question is:

6. What specific challenges are perceived as driving the need for effective human resource management for paid staff and for volunteers?

The above question was developed from research findings from other studies (Rioux \& Bernthal, 1999; Taylor \& McGraw, 2004) on formalisation of HR and tested to see if it holds true for the specific context of non-profit sport organisations.

\section{Method}

\section{Sample}

The NSW Sport Federation, the peak independent representative body for all sport in New South Wales, and the most relevant body for state sporting organisations, was a partner in the study. The Federation represents more than 2.1 million sport participants throughout the state and is most representative of all sport organisation that contain both paid staff and volunteers. The study's sample included all non profit sport organisations who were full members of the 
federation, these include sport organisations which, in the opinion of the Federation's council, are the representative / parent body of that sporting activity in the State.

\section{Procedure}

A total of 125 self-report questionnaires were posted to full member sport organisations using the client database provided by the NSW Sport Federation and addressed to the organisation's Executive Director/General Manager. Follow-up techniques (Dillman, 2000) were used to facilitate a better survey response rate. A total of 54 replies were received but only 43 were deemed usable due to incomplete responses. Although less than ideal, the rate of return (34\%) was considered acceptable, particularly as many sport organisations have few paid staff and typically no dedicated human resource management section. Respondents were Manager/Directors (56\%), Board Members (7\%). The remaining 37\% held a variety of other positions within the organisations. The respondents answered the questions in respect of the human resources management policies, systems and practices that were developed and implemented by the head office, that is, by the state-level governing body.

HR measures derived from existing instrumentation were selected to measure four relevant HR constructs. The selection of the four groups of practices was based on current literature and pilot interviews with managers of eight different sport organisations. The measurement scales for the areas of "selection", "training" and "performance appraisal" were adapted from Wan, Kok and Ong (2002). These scales were selected because they are concise but sufficiently broad to capture the key dimensions of a strategic HRM system. These scales succinctly captured many standard measures of HR and had high internal consistency, ranging from $\alpha=0.77$ to $\alpha=0.94$.

The training scale encompassed "expenditure on training," "different kinds of training are available," "there are opportunities for training," "high priority is placed on training," "there is a systematic training process," and "there is extensive training for general skills." 
One item, "Extensive transference of task and responsibilities" was omitted from the seven training items in the original by Wan et al. after the pilot, as it was found by respondents to be difficult to interpret. The remaining items were deemed sufficient to reflect the extent of the organisation's commitment to staff training and development. The internal consistency of the adapted scale was acceptable; $\alpha=0.948$ for paid staff, and $\alpha=0.932$ for volunteers.

Selection was measured with a 6-item scale adapted from Wan et al. (2002). "We have detailed selection criteria," "we have substantial performance appraisals," "a great deal of effort is expended to select the right person," "great importance is placed on staffing," "selection processes and procedures are extensive," "there is a great deal of money spent on selection." Again one item was omitted after piloting, "Participation in wide range of issues." The items in this scale were broad enough for us to explore the sport organisation's recruitment and selection strategy. The internal consistency of the adapted scale was acceptable; $\alpha=0.842$ for paid staff, and $\alpha=0.872$ for volunteers.

Performance appraisal and reward system for paid staff were measured with a fouritem scale from Wan et al. (2002). Items included "pay rises and promotion are tied to performance," "pay is tied to group/team performance," "performance appraisals are tied to personal development" and "we have performance-based pay incentives." The internal consistency of the adapted scale was $\alpha=0.780$.

The appraisal and reward systems for volunteer staff were measured with a three-item scale derived from Wan et al. (2002). Items included "volunteers are rewarded based on performance," "volunteers are acknowledged for their contribution," and "poor performance by volunteers is acted upon." The internal consistency of the adapted scale was acceptable, $\alpha=0.775$ for volunteers.

The analysis proceeded as follows. First, to determine whether a sport organisation had different approaches to the recruitment and training of paid staff and volunteers, paired 
samples $t$-tests were performed to chart the difference between means for the two sets of scores. As the items concerning payment and reward are different for volunteer staff compared to paid staff, it was inappropriate to make direct comparison between these two constructs. Consequently, these items were analysed separately.

Next, the responses were grouped according to whether or not the organisation had a formalised HR strategy. Responses to the scale and individual items were then compared for both paid staff and volunteers using HR formality as the independent variable. Third, in order to determine whether HR formalisation was an artefact of organisational size, a correlational analysis was undertaken using different measures of size. Organisational size is a complex construct since paid employees (full and part-time), volunteers and even membership (although this was not used in this analysis) could all contribute to competing definitions of size.

For the purposes of this study, organisation size was measured by the number of paid full and part-time staff employed at the time of the survey. This method of estimating size is consistent with the definition of organisation size in the extant HR literature from which the scales are adopted in that it gives most weight to paid staff. However, the number of volunteers can be used as an alternative measure of size in sport organisations. Concomitant with this, an index was constructed adding the number of volunteers into the definition of size. Values of 1.0, 0.5 and 0.1 were assigned to full-time, part-time and volunteer staff respectively, in the construction of this index. A binary logistic regression analysis was then conducted to explore the relative impact of the three variables comprising this index on formality of HRM practices.

Fourth, correlation coefficients were calculated between HR formalisation and perceived organisational effectiveness, for both full- and part-time employees. A further investigation of the relationship between these variables was conducted using binary logistic 
regression analysis with $\mathrm{HR}$ effectiveness as the sole covariate to explain the formalisation of HRM. The fifth and sixth questions in the research concerning future challenges were investigated via qualitative analysis of open ended responses.

\section{Results}

The respondent organisations had an average of 4.3 full-time $(\mathrm{SD}=8.3)$ and 7.6 part-time $(\mathrm{SD}=21.8)$ employees. The average number of volunteers was $531(\mathrm{SD}=1803)$, this number represents a state-wide figure. Membership averages were 5,979 $(\mathrm{SD}=10,806)$ but ranged up to 45,000 . In summary, the respondent organisations were highly diverse in character. The extent to which formal human resource management systems were employed in sport organisations was our first question. Our findings reveal that only $26 \%$ of organisations had a formal HR plan with $74 \%$ indicating that they had no formal plan.

\section{HR Practices for Paid Staff and Volunteers}

The response scores for the training and selection scales, using the whole sample, are presented in Table 1. Higher scores indicate more positive and sophisticated HR processes and practices. Mean scores are clustered in the mid range for both paid staff and volunteers indicating a low level of uptake of HR practices in respondent organisations. The comparison of mean scores for paid staff and volunteers on comparable individual HR items revealed surprisingly few differences. As indicated in Table 1, there are only 3 items: systematic training processes; detailed selection criteria; and extensive selection procedures, with significantly different means.

Table 1 about here

Moreover, there is no strong directional pattern in the data with six items being scored higher for volunteers and seven for paid staff. The significantly different items indicate that staff selection is a high priority for paid staff whereas for volunteers the priority is on extensive training. This pattern is reinforced when comparing the scales overall. The 
composite training and selection scales revealed significantly different HR patterns for paid staff and volunteers. Training of paid staff had a significantly lower summed response mean $(\mathrm{M}=2.57$, S.D. $=1.48)$, than did training of volunteers $(\mathrm{M}=3.07, \mathrm{~S} . \mathrm{D} .=1.57)$, whereas for selection practices this was reversed, with the paid staff being higher $(\mathrm{M}=3.18$, S.D. $=1.69)$, than volunteers $(M=2.74$, S.D. $=1.71)$. An independent samples $t$-test indicates a significant difference $(\mathrm{p}<.01)$.

Analyses of the individual HR items using formalisation as the independent variable revealed substantial differences in the approach to HR for paid staff and volunteers, as can be seen from Table 2.

Table 2 about here

The HR practices of organisations with and without formal HR plans were compared via a series of $t$-tests. In twelve of the twenty-four practices measured, organisations with formal HR policies report higher levels of the practice than do organisations without formal HR policies $(2.02<t<3.73, p<.05)$. Of these twelve significantly different practices, ten relate to the management of paid staff.

Summarising the results for our first three research questions, the analysis of the data suggests that fewer than one quarter of the organisations have formal HR policies, and that whilst there are differences in the way that paid staff and volunteers are managed, this is most clearly evident in organisations that have formal HR policies. It seems reasonable to suggest, therefore, that it is HR formality that is the crucial variable in predicting differences in the way that paid staff and volunteers are managed.

This leads to the consideration of our fourth research question, that is, whether having a formal HR strategy was related to organisational size. Results using our first measure of organisational size (the combined number of full- and part-time paid staff) and HR formality revealed no significant correlation between size and HR formality $(r=-.178, p=.272)$. The 
correlation between the second measure of size (the index including number of volunteers as well as paid staff) and HR formality also failed to reveal a significant relationship ( $p=$ 0.475). Next, a binary logistic model was built to explore the impacts of the actual numbers of full, part-time, and volunteer staff on HRM formality. The results of this analysis are presented in Table 3.

\section{Table 3 about here}

As an examination of Table 3 indicates, the number of paid, full-time employees was the only significant predictor that an organisation had formal HR policies. In particular, the negative coefficient of full-time employees (-0.280) suggests that the larger the number of paid full time employees, the slightly more likely that the organisation will have a formal HRM system. This relationship is marginally significant $(p=0.047)$.

The very large $p$-values of the numbers of part-time employees and volunteers suggest that there is no significant relationship between the numbers of part time employees or volunteers and the formalisation of HRM. Thus, when using the broader composite measure for organisation size, we found that size is not related to formalisation of HR. On the basis of this analysis, we can reasonably conclude that the only significant variable influencing formalisation of HR in terms of organisation size is the number of paid full-time employees.

Our fifth research question concerned the relationship between the existence of formal HR policies and the perceived effectiveness of the organisation in managing staff. In the first instance, box-plots were drawn to compare perceived effectiveness of HRM for paid staff and volunteers in organisations with formal HRM and those without formal HRM. This revealed that for paid-staff, organisations with formal HRM had higher means $(M=6.33, S . D=2.0)$ than did organisations without formal HRM and a lesser variance of rating scores $(\mathrm{M}=5.32$, $S . D=2.50$ ). For volunteers the pattern was similar, organisations with formal HRM had 
mean scores of 5.90 ( $\mathrm{S} . \mathrm{D}=1.30)$ whilst those without formal HRM had mean scores of 4.93 $(\mathrm{S} . \mathrm{D}=1.94)$

However, Pearson correlation reveals no relationship between formal HR processes and perceived effectiveness in the management of paid staff $(r=-0.177, p=0.275)$. Similarly, no relationship was observed for volunteers $(r=0.236, p=0.133)$. For further analysis, a binary logistic regression model was built with "effectiveness" as the sole covariate to explain the formalisation of HRM. The indicator variable of "effectiveness" was not significant; leading us to conclude that there is no observable relationship between having a formal HRM system and the perceived effectiveness the organisations' current approach to HR for paid staff. The same procedures were used to test for a relationship between formal HR processes for volunteers and perceived effectiveness of HR systems. Similar to paid staff, the analysis revealed no relationship between perceived effectiveness of the organisations' HR for volunteers and HR formalisation.

\section{Human Resource Management Challenges}

In response to our final question, survey respondents were asked to rank the top three challenges driving the adoption of formal HRM in their organisation. The list was generated from the literature and the initial pilot testing of the survey and included nine items: (1) desire to improve business results; (2) retirement of current managers; (3) new CEO or leadership changes; (4) anticipated changes in skills of future leaders; (5) organisation growth or expansion; (6) need for greater diversity; (7) to increase retention; (8) to fill a vacancy; and (9) demands in the organisation creating new skill requirements. We were interested in ascertaining if the challenges driving the need for effective human resource management were perceived to be the same for practices concerning paid-staff and volunteers.

In analysing the reported prerequisites for formal HR practices for paid employees, organisation growth was ranked highest, followed by new skill requirements, and the 
improvement of business results. In terms of volunteer HR, the drivers were firstly, organisation growth; and secondly, filling vacancies left by departures. Organisations with formal HR plans ranked the improvement of business results, together with organisation growth, as equally important for the development of formal HR for paid staff, and organisation growth as the primary reason for engaging in formal HR for volunteers. In sport organisations with no formal HR practices, organisation growth was likewise ranked as the main reason for formalising paid employee HR, and the need for greater diversity was the most commonly nominated reason for formalising volunteer HR.

\section{Discussion}

In this paper we have presented data outlining human resource management systems and practices in state level representative sport organisations. Strategic human resource management sophistication has been captured using the concept of formalisation, underpinned by associated functions and practices. We have argued that professionalisation, increases in the number of paid staff, changes in government policy and funding criteria, and an increasingly strict compliance climate during the past decade have encouraged, and in certain cases necessitated, formalised HRM (Nichols et al., 1998). Our first research question, therefore, was to what extent HR formalisation has occurred in sport organisations. The impact of these factors has been uneven, and has resulted in the development of formal HR plans and systems in only a small proportion, approximately one-quarter, of sport organisations. This finding shows that Australian sport organisations lag behind mainstream business organisations in their uptake of formal HR policies and practices (McGraw, 2002).

In investigating our second and third research questions about the HR practices used by sport organisations, we examined the overall usage as well as distinctive features employed in the management of paid staff and volunteers. When analysed as a whole, the 
sport organisations responding to this study showed a low level of overall takeup of HR practices, and few significant differences in practices related to paid staff and volunteers, with only three HR practice items out of twelve having significantly different means. The generally low level of HR practice implementation aligns with the view of the Australian Sports Commission (2000) which suggested that sport organisations would have minimal HR practices for paid staff and volunteers.

With regard to paid staff, the research findings highlight three key aspects of the way that people are managed. First, there is a strong emphasis placed on the recruitment and selection of paid staff, but the facilitation of further employee development is not widely supported via formal systems of training. Second, the emphasis on recruitment and selection rather than on training and development may reflect the changing nature of sport organisation workforce requirements and the funding limitations of these organisations. As the industry professionalises, staff are expected to be knowledgeable and passionate about the specific sport that the organisation represents, and to also have relevant business and management skills and expertise. Therefore, instead of putting resources into training existing staff, sport organisations may feel that a significant personnel change is required, and may look to recruitment of new staff to meet new sport management requirements. Third, the extra resources put into recruiting and selecting paid employees suggests that sport organisations generally believe that employing the right people will pay off in the long run.

In relation to volunteers, more attention was paid to their training and less attention to recruiting and selecting when compared to practices for paid staff. There are a number of possible reasons for this. First, in selecting volunteers, sport organisations are in many cases recruiting people without high levels of expertise to join the organisation. Often they are not selecting, but rather are accepting people willing to give up their time. Implicit in this is the notion that volunteers will receive basic training. Second, because volunteer numbers are 
declining, there is probably now more pressure than ever on sport organisations to take all who volunteer, even if they are not specifically skilled in the area for which they are recruited. Thus there is a need for more developmental training. Third, there are also statutory requirements to train volunteers in relation to compliance issues. In the case of paid staff, these responsibilities may be inculcated over time and on the job and hence not be seen as specific training issues. Moreover, because of laws regulating employment, the organisation is vicariously liable for the actions of paid staff and hence more able to legitimately and directly control their behaviours. On the other hand, the liability for volunteers is less clearly defined, and the responsibilities have to be more indirectly inculcated via training.

These findings would tend to support the arguments introduced at the beginning of this paper that HR practices from complex business organisation do not easily transfer to sport organisations. The development of formal HR plans is likely to be constrained by, among other factors, the lack of a long-term perspective on issues such as recruitment, appraisal, provision of training and development. Sport organisations face tensions between formality and informality of such practices. The use of informal approaches can provide a strong sense of teamwork, enhance social connections and increase employee and volunteer motivation (Barber et al., 1999; Bartram, 2004; de Kok \& Uhlaner, 2001; Marlow \& Patton, 2001). On the other hand, formal approaches can provide transparency, consistency and clarity for staff. The challenge is to provide HRM that facilitates positive and motivating environments but does not depersonalise or unnecessarily regiment the experience of employees and volunteers. This study has highlighted which HRM practices sport organisations are adopting as they grapple with balancing these tensions.

The use of HRM policy and practices to improve business outcomes and provide competitive advantage (Becker et al., 1998; Pfeffer, 1998) is clearly not being adopted by the 
sport organisations participating in this study. This could reflect the employment of a contingency based approach to HR (Purcell, 1999) or, more likely, an approach reflecting an under-resourced and ad hoc approach to HRM which is predominantly at odds with the expectations from external stakeholders, that sport organisations in Australia should be managed professionally using techniques imported directly from the business world.

Unexpectedly, we found that overall organisation size was not related to the degree of formalisation of HR practices. This is inconsistent with findings from other industry sectors, where larger organisations are more likely to have formal HR systems (Goodstein, 1994; Ingram \& Simons, 1995; McGraw, 2002). In addition, there was no relationship between the perceived effectiveness of staff/volunteer management and the presence, or lack of, a formal HR strategy. This aligns with more general studies conducted on strategic HRM in Australia which also reveal that the goals of HRM are not achieved in practice (Kane, Crawford, \& Grant, 1999). Nonetheless, basic HR compliance practices are being externally mandated, thereby requiring the development of, at the very least, rudimentary HR processes. In this respect, the sport organisations in our study were using a range of recruitment practices for paid employees although by and large, they recruited volunteers by word of mouth. This finding is consistent with comments made by the Australian Sports Commission (2000) that volunteers are unlikely to be managed formally. Some formal training and development practices are being applied, but performance management practices are uncommon.

The final research question asked organisations to identify specific challenges that would necessitate the use of effective human resource management techniques. The primary challenge identified by all organisations was organisational growth. The often cited (Cuskelly, 2004; Kikulis, 2000; Taylor et al., 1996) need to comply with externally mandated change from government was not viewed by our respondent organisations as a key driver of HR professionalisation. Secondary challenges identified by the organisations in this study 
driving the formalisation of HR practices were new skill requirements, the need to improve organisational effectiveness and remain attractive to paid staff and volunteers and demographic shifts such as an ageing population and increasing diversity. A study of corporate sector companies in Australian found that improving business results was the key driver for strategic HRM implementation, followed closely by responding to new business opportunities (Taylor \& McGraw, 2004).

Some important limitations of this study should be noted. First, the study did not directly measure organisational performance and therefore we cannot comment definitively on the link between organisational effectiveness and the use of formal HR. Second, we relied exclusively on respondent interpretations, thus we only gained one perspective about HR and only a management viewpoint. Therefore, future studies would do well to combine selfreport, informant-report, as well as interview-based and observational methodologies, in order to more fully assess the key constructs in this investigation. Expansion of this study using qualitative methods would greatly add to the explanatory aspect of the data. In particular, it would be interesting to investigate the factors influencing the adoption of formal HRM by some sport organisations but not by others.

\section{Conclusions}

This research furthers our understanding of human resource practices in sport organisations by employing measures from the general business literature to interpret the management of people in sport organisations. The broad conclusion drawn is that sport organisations deploy HRM in a relatively unsophisticated way. A strong differentiation is noted between organisations with formal HR policies and those without. Previous work on volunteers in sport has explored individual commitment, motivations and characteristics of volunteers (Coleman, 2002; Cuskelly, 2004; Metzer, 1996; Taylor et al., 1996). This study extends this work by detailing the specific HR practices deployed in the management of 
volunteers in sport organisations, albeit in one country, and contrasting these with practices used with paid employees. The critical factor differentiating the management of the two groups is formalisation of HRM, which we employed in this study as a proxy for human resource sophistication. In the future, changes in labour force and volunteer base participation, public liability issues and mandatory volunteer contracts may contribute to an obscuring of the volunteer-employee distinction. The human resource management challenge will be to build a sound participatory base for volunteer and paid employees that rewards, recognises, and empowers individuals while meeting the rapidly changing needs and requirements of the sport organisation.

This study has implications for public policy in Australia and other countries where representative non-profit sport organisations face similar challenges. While current sport policy in many western countries, including Australia, Canada and the United Kingdom, stipulates the need for organisations to develop formal HR practices, our research suggests that few organisations have responded fully to this directive. This implies that the government, if serious about pursuing this agenda, should provide support and training programs that assist with the development of more strategic and formal practices. Additionally, while there is a generic push for formal HR, there is little recognition that different sport organisations will have different requirements; one size will not fit all. Finally, and of critical importance, is the need for empirical research to better understand the link between formal HR practices and organisational performance, a research challenge that remains to be tackled. 


\section{References}

Applebaum, E., Bailey, T., Berg, P., \& Kalleberg, A.L. (2000). Manufacturing advantage: Why high performance work systems pay off. London: Cornell University Press.

Auld, C. (1997). Professionalisation of Australian sport: The effects on organisational decision making. European Journal for Sport Management, 4(2), 17-39.

Australian Bureau of Statistics. (2000). Voluntary work Australia. Canberra: Commonwealth of Australia.

Australian Bureau of Statistics. (2001). Involvement in organised sport and physical activity. Canberra: Commonwealth of Australia.

Australian Bureau of Statistics. (2005). Involvement in organised sport and physical activity, Australia. Canberra: Commonwealth of Australia.

Australian Government. (2001). Backing Australia's sporting ability: A more active Australia. Canberra: Australian Government.

Australian Sports Commission. (2000). Active Australia volunteer management program Recruiting volunteers. Canberra: Australian Sports Commission.

Barber, A. E., Wesson, M. J., Roberson, Q. M., \& Taylor, M. S. (1999). A tale of two job markets: Organisational size and its effects on hiring practices and job search behavior. Personnel Psychology, 52, 841-867.

Barney, J. B. (1991). Firm resources and sustained competitive advantage. Journal of Management, 17(1), 99-120.

Bartram, D. (2004). Assessment in Organisations. Applied Psychology: An International Review, 53(2), 237-259.

Beech, J., \& Chadwick, S. (Eds.) (2004). The business of sport management. London: Prentice Hall. 
Becker, B. E., Huselid, M. A., Pickus, P. S. \& Spratt, M. (1998). High performance work systems and firm performance: A synthesis of research and managerial implications. In Research in Personnel and Human Resources Management (vol. 16, pp. 53-101), Stamford, CA: JAI Press.

Boxall, P., \& Purcell, J. (2000). Strategic human resource management: Where have we come from and where should we be going? International Journal of Management Reviews, 2(2), 183-203.

Burgham, M., \& Downward, P. (2005). Why volunteer, time to volunteer? A case study from swimming. Managing Leisure, 10(2), 79-93.

Buswell, J. (2004). Sport and leisure service encounter. In U. McMahon-Beattie \& I. Yeoman (Eds.), Sport and leisure operations management (pp. 3-35). London: Thomson.

Chelladurai, P. (1999). Human resource management in sport and recreation. Champaign, IL: Human Kinetics.

Coleman, R. (2002). Characteristics of volunteering in UK sport: Lessons from cricket. Managing Leisure, 7(4), 220-238.

Cook, D. S. \& Ferris,G. R. (1986) Strategic human resource management and firm effectiveness in industries experiencing decline. Human Resource Management, 25(3), $110-126$.

Cuskelly, G. (2004). Volunteer retention in community sport organisations. European Sport Management Quarterly, 4(2), 59-76.

Cuskelly, G., McIntyre, N., \& Boag, A. (1998). A longitudinal study of the development of organisational commitment amongst volunteer sport administrators. Journal of Sport Management, 12, 181-202.

de Kok, J., \& Uhlaner, L. (2001). Organisation context and human resource management in the small firm. Small Business Economics, 17(4), 273-291. 
Dillman, D.A. (2000). Mail and internet surveys: The tailored design method. New York: Wiley.

Department of Sport \& Recreation. (2004). Valuing volunteers in sport and recreation. Perth: Western Australian Department of Sport \& Recreation.

Doherty, A.J. (1998). Managing our human resources: A review of organisational behaviour in sport. Sport Management Review, 1, 1-24.

Doherty, A. J., \& Carron, A. V. (2003). Cohesion in volunteer sport executive committees. Journal of Sport Management, 17, 116-141.

Doherty, A. J., Patterson, M., \& Van Bussel, M. (2004). What do we expect? An examination of perceived committee norms in non-profit sport organisations. Sport Management Review, 7, 109-132.

Dorsch, K., Riemer, H., Paskevich, D., Chelladural, P., Sluth, V., \& Choptain, N. (2002). Differences in volunteer motives based on organisation type and level of involvement. In 17th Annual North American Society for Sport Management Conference. NASSM Abstracts, (p.28). Canmore, Alberta: North American Society for Sport Management.

Galang, M. (2004). The transferability question: Comparing HRM practices in the Philippines with the US and Canada. International Journal of Human Resource Management, 15, $1207-1233$.

Goodstein, J.D. (1994). Institutional pressures and strategic responsiveness: Employer involvement in work-family issues. Academy of Management Journal, 37, 350-382.

Gratton, L., \& Truss, C. (2003). The three-dimensional people strategy: Putting human resources policies into action. Academy of Management Executive, 17(3), 74-86.

Green, L. (2001). Valuing volunteers in sport and recreation: A guide to good practice, Brisbane: The State of Queensland (Department of Innovation and Information Economy, Sport and Recreation Queensland). 
Guest, D. (1987). Human resource management and industrial relations. Journal of Management Studies, 24, 503-521.

Hoye, R., \& Cuskelly, G. (2003). Board power and performance within voluntary sport organisations. European Sport Management Quarterly, 3(2),103-119.

Hsu, Y.R., \& Leat, M. (2000). A study of HRM and recruitment and selection policies and practices in Taiwan. International Journal of Human Resource Management, 11, 413435.

Huselid, M. (1995). The impact of human resource management practices on turnover, productivity, and corporate financial performance. Academy of Management Journal, 38, 653-672.

Huselid, M. A., \& Becker, B. E. (2000). Comment on "measurement error in research on human resources and firm performance: How much error is there and how does it influence effect size estimates?” In B. Gerhart, P. M., Wright, G. C., McMahan \& S. A. Snell (Eds.), Personnel Psychology, 53, 835-854.

Inglis, S. (1997). Roles of the board in amateur sport organisations. Journal of Sport Management, 11, 160-176.

Ingram, P. \& Simons, T. (1995). Institutional and resource dependence determinants of responsiveness to work-family issues. Academy of Management Journal, 38, 1466-1482.

Kane, R.L., Crawford, J., \& Grant, D. (1999). Barriers to effective HRM. International Journal of Manpower, 20, 494-515.

Kaye, L. (1999). Strategic human resources management in Australia: The human cost. International Journal of Manpower, 20, 577-587.

Kikulis, L. (2000). Continuity and change in governance and decision making in national sport organisations: Institutional explanations. Journal of Sport Management, 14, 293 320. 
Kikulis, L.M., Slack, T., \& Hinings, C.R. (1995a). Does decision making make a difference? Patterns of change within Canadian national sport organisations. Journal of Sport Management, 9, 273-299.

Kikulis, L.M., Slack, T., \& Hinings, C.R. (1995b). Sector-specific patterns of organisational design change. Journal of Management Studies, 32(1), 67-100.

Kikulis, L.M., Slack, T., \& Hinings, C.R. (1995c). Toward an understanding of the role of agency and choice in the changing structure of Canada's national sport organisations. Journal of Sport Management, 9, 135-152.

Koch, J., \& McGrath, R. G. (1996). Improving labor productivity - Human resource management policies do matter. Strategic Management Journal, 17, 335-354.

Leung, A. (2004). Different ties for different needs: Recruitment practices of entrepreneurial firms at different developmental phases. Human Resource Management, 42, 303-320.

McGraw, P. (2002). The HR function in local and overseas firms: Evidence from the Pricewaterhouse Coopers-Cranfield HR Project (1999), Asia Pacific Journal of Human Resources, 40(2), 1-24.

McClam, T. \& Spicuza, F. (1988). An unholy alliance: The professional-volunteer relationship. Nonprofit World, 6(3), 25-7.

Marlow, S., \& Patton, D. (2002). Minding the gap between employers and employees: The challenge for owner-managers of smaller manufacturing firms. Employee Relations, 24, 523-539.

Metzer, J. (1996). The psychology of volunteering: External or internal rewards? Australian Journal of Volunteering, 1(2), 20-24.

Miller, L. E., Powell, G. N. \& Seltzer, J. (1990) Determinants of turnover among volunteers. Human Relations, 43, 901-917. 
Nichols, G., Gratton, C., Shibli, S., \& Taylor, P. (1998). Local authority support to volunteers in sports clubs. Managing Leisure, 3(3), 119-127.

Nguyen, T., \& Bryant, S. (2004). A study of the formality of human resource management practices in small and medium-size enterprises in Vietnam. International Small Business Journal, 22, 595-618.

Pfeffer, J. (1998). The human equation: Building profits by putting people first. Boston: Harvard Business School Press.

Purcell, J. (1999). Best practice and best fit: chimera or cul-de-sac. Human Resource Management Journal, 9(3), 26-41.

Rioux, S., \& Bernthal, P. (1999). Succession management practices survey report. Pittsburgh, PA: HR Benchmark Group.

Sisson, K., \& Storey, J. (2000). The realities of human resource management. Maidenhead: Open University Press.

Slack, T., \& Hinings, B. (1994). Institutional pressures and isomorphic change: An empirical test. Organisation Studies, 15, 803-827.

Slack, T., \& Hinings, B. (1992). Understanding change in national sport organisations: An integration of theoretical perspectives. Journal of Sport Management, 6, 114-132.

Sport \& Recreation Victoria. (2002). User-friendly sport - An ideas book to help sport and recreation clubs grow. Melbourne: State of Victoria.

Storey, J. (2001). Human resource management: A critical text, (2nd ed.). London: Thomson Learning.

Taylor, P., Shibli, S., Michels., G., \& Gratton, C. (1996). Valuing volunteers in UK sport, A Sports Council survey into the voluntary sector in UK. Sheffield: Leisure Industries Research Centre. 
Taylor, T., \& McGraw, P. (2004) Succession management practices in Australian organizations. International Journal of Manpower, 25, 741-758.

Thibault, L., Slack, T., \& Hinings, B. (1991). Professionalism, structures and systems: The impact of professional staff on voluntary sport organisations. International Review for the Sociology of Sport, 26, 83-97.

Truss, C. (2001). Complexities and controversies in linking HRM with organisational outcomes. Journal of Management Studies, 38, 1121-1149.

Wan, D., Kok, V., \& Ong, C. (2002). Strategic human resource management and organisational performance in Singapore. Human Resource Management, 34(4), 33-42.

Wright, P.C., \& Geroy, G.D. (2001). Changing the mindset: The training myth and the need for world-class performance. International Journal of Human Resource Management, 12, 586-600. 
Table 1. HR practices for paid staff versus volunteers: means and $t$ - tests $(n=43)$

\begin{tabular}{|c|c|c|c|c|c|c|}
\hline \multirow[t]{2}{*}{ HR practice } & \multicolumn{2}{|c|}{ Paid staff } & \multicolumn{2}{|c|}{ Volunteers } & \multirow[t]{2}{*}{$t$} & \multirow[t]{2}{*}{$p$-value } \\
\hline & Mean & S.D & Mea & S.D & & \\
\hline \$ Spent on Training \& Development & 2.65 & 1.21 & 2.70 & 1.22 & -.160 & .873 \\
\hline Variety of Training \& Development & 2.82 & 1.43 & 3.31 & 1.37 & -1.542 & .127 \\
\hline Training \& Development opportunities & 3.25 & 1.42 & 3.76 & 1.36 & -1.621 & .109 \\
\hline Priority on Training \& Development & 2.95 & 1.50 & 3.42 & 1.51 & -1.378 & .172 \\
\hline Systematic Training \& Development & 2.10 & 1.23 & 2.92 & 1.54 & -2.617 & $.011^{*}$ \\
\hline Extensive Training \& Development & 2.42 & 1.38 & 3.11 & 1.55 & 2.017 & $.047^{*}$ \\
\hline Detailed Selection Criteria & 3.40 & 1.61 & 2.99 & 1.91 & 1.019 & .311 \\
\hline Substantial Performance Appraisals & 2.94 & 1.65 & 2.38 & 1.41 & 1.591 & .116 \\
\hline Effort Select Right Person & 4.04 & 1.47 & 3.43 & 1.95 & 1.550 & .125 \\
\hline Importance of Staffing & 3.75 & 1.54 & 3.50 & 1.52 & .709 & .481 \\
\hline Extensive Selection Processes & 3.45 & 1.41 & 2.70 & 1.43 & 2.304 & $.024^{*}$ \\
\hline Money Spend on Selection & 2.35 & 1.31 & 1.92 & 1.21 & 1.472 & .145 \\
\hline Pay Tied to Team Performance & 2.15 & & & & & \\
\hline Performance Appraisals Tied to Per Devel & 2.64 & & & & & \\
\hline Performance Based Incentives Used & 1.64 & & & & & \\
\hline Volunteers Rewarded on Performance & & & 2.51 & & & \\
\hline Volunteer Contributions Acknowledged & & & 4.73 & & & \\
\hline Poor Volunteer Performance Acted Upon & & & 3.29 & & & \\
\hline
\end{tabular}

${ }^{*} p<0.05$ 
Table 2. Mean Differences of HR Practices by Formal versus Informal HR Policies

\begin{tabular}{|c|c|c|c|c|c|}
\hline HR Practice & HR Strategy & Mean & $t$ & $p$-value & Std. Error \\
\hline \multirow[t]{2}{*}{ Sig \$ Training \& Develop-pd } & Yes & 3.09 & \multirow[b]{2}{*}{1.333} & \multirow[b]{2}{*}{.191} & \multirow[b]{2}{*}{.430} \\
\hline & No & 2.51 & & & \\
\hline \multirow[t]{2}{*}{ Sig \$ Training \& Develop-vol } & Yes & 3.12 & \multirow{2}{*}{1.049} & \multirow[b]{2}{*}{.302} & \multirow[b]{2}{*}{.494} \\
\hline & No & 2.60 & & & \\
\hline \multirow[t]{2}{*}{ Variety Training \& Develop-pd } & Yes & 3.63 & \multirow[b]{2}{*}{2.217} & \multirow[b]{2}{*}{$.033^{*}$} & \multirow[b]{2}{*}{.480} \\
\hline & No & 2.57 & & & \\
\hline \multirow[t]{2}{*}{ Variety Training \& Develop-vol } & Yes & 3.22 & \multirow[b]{2}{*}{-.397} & \multirow{2}{*}{.694} & \multirow{2}{*}{.520} \\
\hline & No & 3.43 & & & \\
\hline \multirow[t]{2}{*}{ Training \& Develop Opps-pd } & Yes & 4.09 & \multirow[b]{2}{*}{2.338} & \multirow[b]{2}{*}{$.025^{\star}$} & \multirow[b]{2}{*}{.482} \\
\hline & No & 2.96 & & & \\
\hline \multirow[t]{2}{*}{ Training \& Develop Opps-vol } & Yes & 4.11 & \multirow[b]{2}{*}{.762} & \multirow[b]{2}{*}{.451} & \multirow[b]{2}{*}{.521} \\
\hline & No & 3.71 & & & \\
\hline \multirow[t]{2}{*}{ Priority Training \& Develop-pd } & Yes & 3.82 & \multirow[b]{2}{*}{2.689} & \multirow[b]{2}{*}{$.012^{*}$} & \multirow[b]{2}{*}{.437} \\
\hline & No & 2.64 & & & \\
\hline \multirow[t]{2}{*}{ Priority Training \& Develop-vol } & Yes & 3.89 & \multirow{2}{*}{.974} & \multirow{2}{*}{.337} & \multirow{2}{*}{.583} \\
\hline & No & 3.32 & & & \\
\hline \multicolumn{2}{|c|}{ SystematicTraining \& Develop-pdYes } & 3.00 & \multirow{2}{*}{3.037} & & \\
\hline & No & 1.78 & & $.004^{\star \star}$ & .400 \\
\hline SystematicTraining \& Develop- & -VolYes & 3.78 & & & \\
\hline & No & 2.62 & 2.029 & $.050^{\star}$ & .570 \\
\hline Extensive Training \& Develop-p & pd Yes & 3.22 & & & \\
\hline & No & 2.18 & 2.020 & $.050^{*}$ & .517 \\
\hline SystematicTraining \& Develop- & -volYes & 3.75 & & & \\
\hline & No & 2.89 & 1.375 & .178 & .623 \\
\hline
\end{tabular}

${ }^{*} \mathrm{P}<0.05,{ }^{* *} \mathrm{P}<0.01$ 


\section{Continued}

\begin{tabular}{|c|c|c|c|c|c|}
\hline HR Practice & AR Strategy & Mean & $t$ & $p$-value & Std. Error \\
\hline \multirow[t]{3}{*}{ Detailed selection criteria - paid } & Yes & 4.45 & \multirow{3}{*}{2.729} & \multirow{3}{*}{$.010^{\star *}$} & \multirow{3}{*}{.540} \\
\hline & & & & & \\
\hline & No & 2.98 & & & \\
\hline \multirow[t]{2}{*}{ Detailed selection criteria - vol } & Yes & 4.00 & \multirow[b]{2}{*}{1.864} & \multirow[b]{2}{*}{.071} & \multirow[b]{2}{*}{.718} \\
\hline & No & 266 & & & \\
\hline \multirow[t]{2}{*}{ Substantial performance appr - paid } & id Yes & 3.54 & \multirow{3}{*}{1.340} & \multirow{3}{*}{.189} & \multirow{3}{*}{.581} \\
\hline & $\mathrm{Nh}$ & 277 & & & \\
\hline & & & & & \\
\hline \multirow[t]{3}{*}{ Substantial performane appr - vol } & Yes & 2.66 & \multirow{3}{*}{.600} & \multirow{3}{*}{.553} & \multirow{3}{*}{.546} \\
\hline & & & & & \\
\hline & No & 2.34 & & & \\
\hline \multirow[t]{2}{*}{ Effort select right person - paid } & Yes & 5.09 & \multirow[b]{2}{*}{3.731} & \multirow[b]{2}{*}{$.001^{* *}$} & \multirow[b]{2}{*}{.371} \\
\hline & No & 3.70 & & & \\
\hline \multirow[t]{2}{*}{ Effort select right person - vol } & Yes & 4.33 & \multirow[b]{2}{*}{1.533} & \multirow[b]{2}{*}{.134} & \multirow[b]{2}{*}{.742} \\
\hline & No & 3.19 & & & \\
\hline \multirow[t]{2}{*}{ Importance staffing - paid } & Yes & 4.54 & \multirow[b]{2}{*}{2.362} & \multirow[b]{2}{*}{$.026^{\star}$} & \multirow[b]{2}{*}{.458} \\
\hline & No & 3.46 & & & \\
\hline \multirow[t]{2}{*}{ Importance staffing - vol } & Yes & 4.00 & \multirow[b]{2}{*}{1.015} & \multirow[b]{2}{*}{.317} & \\
\hline & $\mathrm{No}$ & 337 & & & .620 \\
\hline Extensive selection process - paid & Yes & 4.36 & & & \\
\hline & & & 2.601 & $.013^{*}$ & .456 \\
\hline & No & 3.18 & & & \\
\hline Extensive selection process - vol & Yes & 3.78 & & & \\
\hline & No & 2.41 & 2.724 & $.010^{*}$ & .503 \\
\hline Money spent on selection - paid & Yes & 3.30 & & & \\
\hline & No & 2.05 & 2.257 & $.044^{*}$ & .552 \\
\hline Money spent on selection - vol & Yes & 2.62 & & & \\
\hline & & & 1.854 & .072 & .472 \\
\hline & No & 1.75 & & & \\
\hline
\end{tabular}

${ }^{*} \mathrm{P}<0.05,{ }^{* *} \mathrm{P}<0.01$ 
Table 3: Logistic Regression for organisation size and HRM

\begin{tabular}{lcrcr}
\hline Predictor & \multicolumn{1}{c}{$B$} & Wald $\chi^{2}$ & $p$ & $\operatorname{Exp}(B)$ \\
\hline F/T Employees & -.280 & 3.932 & .047 & .756 \\
P/T Employees & .019 & .444 & .505 & 1.020 \\
Volunteers & .006 & .694 & .405 & 1.006 \\
Constant & 1.715 & 5.847 & .016 & 5.555
\end{tabular}

